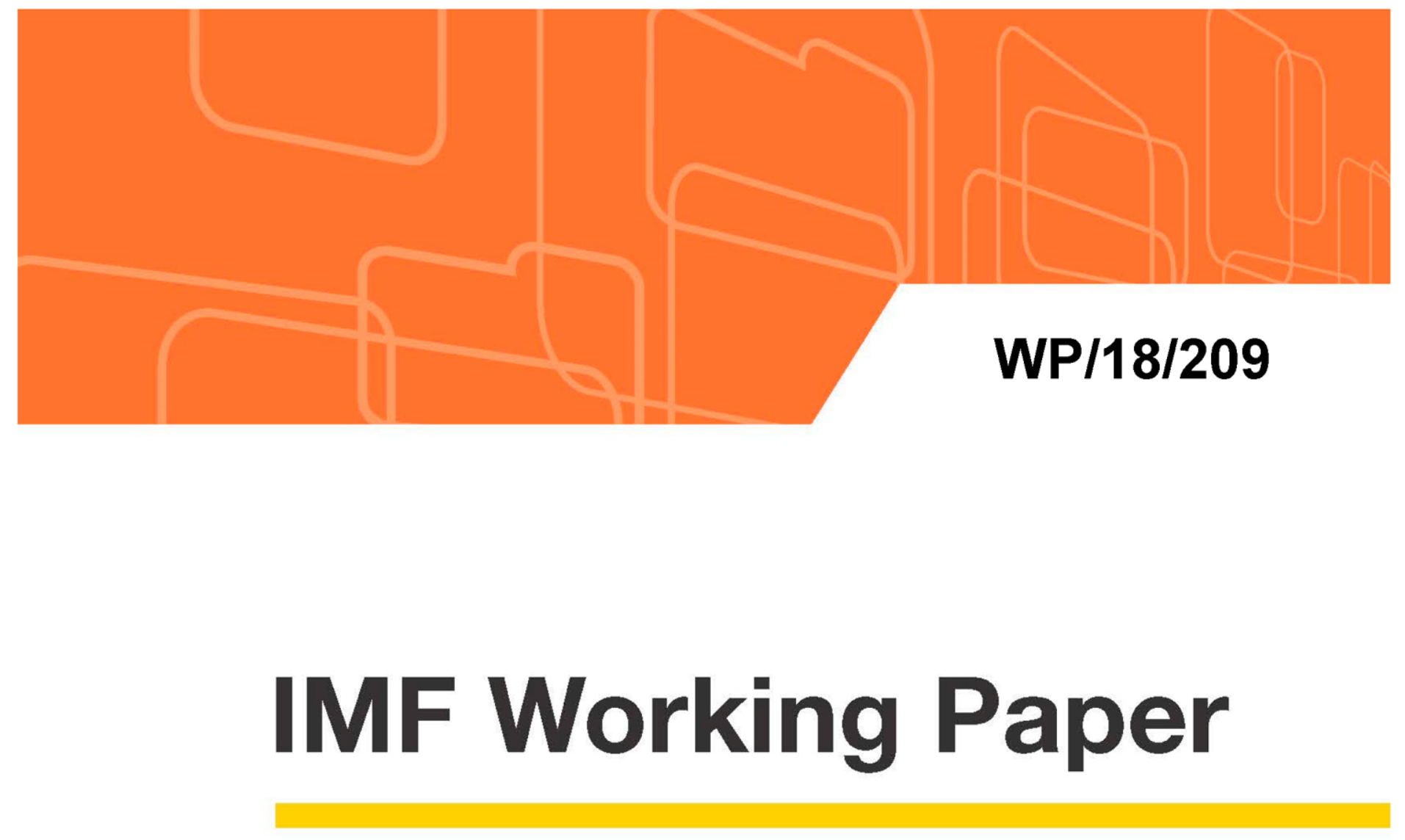

\title{
House Price Synchronization and Financial Openness: A Dynamic Factor Model Approach
}

by Mitsuru Katagiri

IMF Working Papers describe research in progress by the author(s) and are published to elicit comments and to encourage debate. The views expressed in IMF Working Papers are those of the author(s) and do not necessarily represent the views of the IMF, its Executive Board, or IMF management. 


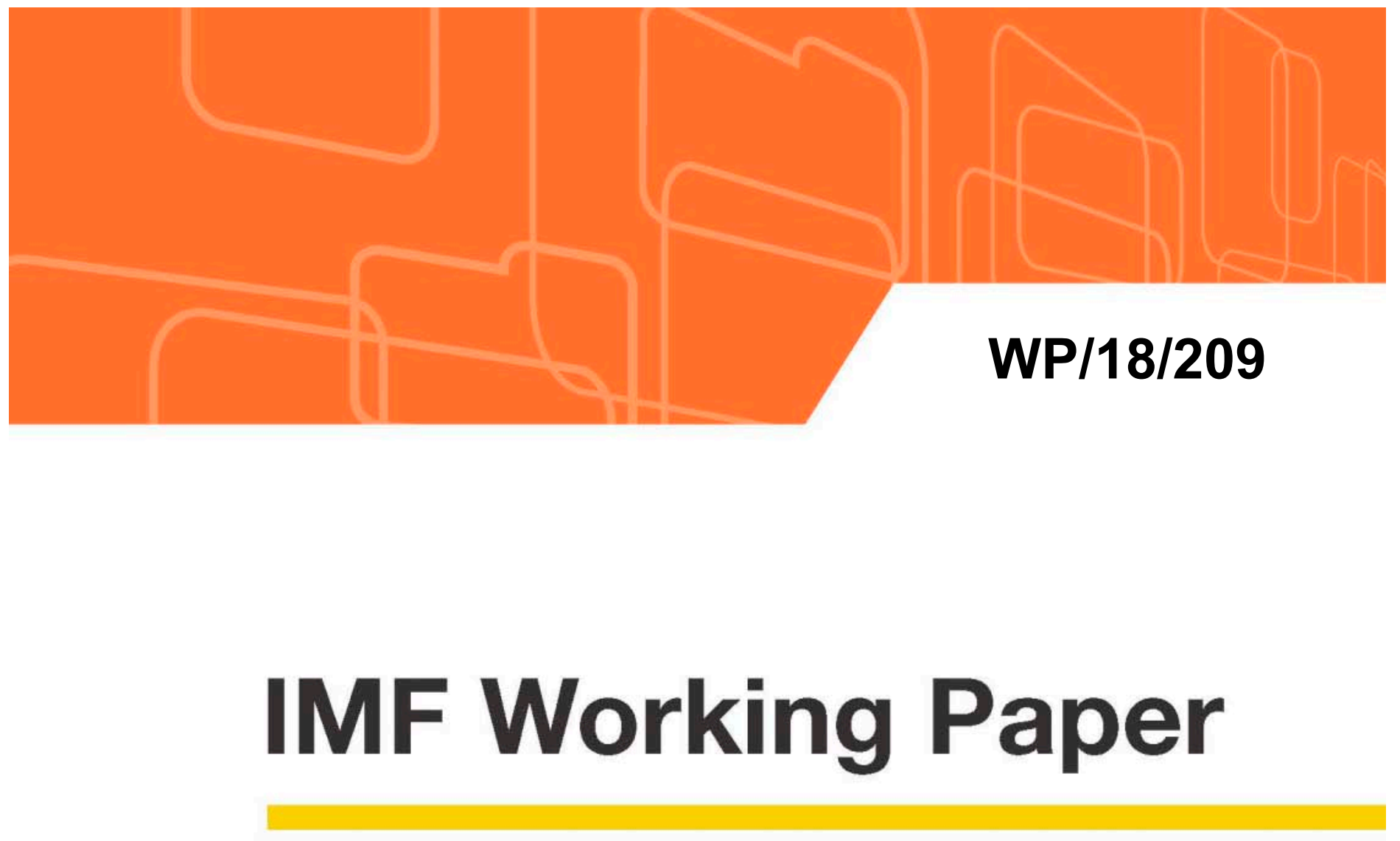

\title{
House Price Synchronization and Financial Openness: A Dynamic Factor Model Approach
}

\author{
by Mitsuru Katagiri
}

IMF Working Papers describe research in progress by the author(s) and are published to elicit comments and to encourage debate. The views expressed in IMF Working Papers are those of the author(s) and do not necessarily represent the views of the IMF, its Executive Board, or IMF management. 


\title{
IMF Working Paper
}

Monetary and Capital Markets Department

\section{House Price Synchronization and Financial Openness: A Dynamic Factor Model Approach}

\section{Prepared by Mitsuru Katagiri*}

Authorized for distribution by Claudio Raddatz

September 2018

\section{IMF Working Papers describe research in progress by the author(s) and are published to elicit comments and to encourage debate. The views expressed in IMF Working Papers are those of the author(s) and do not necessarily represent the views of the IMF, its Executive Board, or IMF management.}

\begin{abstract}
This paper investigates the developments in house price synchronization across countries by a dynamic factor model using a country- and city-level dataset, and examines what drives the synchronization. The empirical results indicate that: (i) the degree of synchronization has been rising since the 1970s, and (ii) a large heterogeneity in the degree of synchronization exists across countries and cities. A panel and cross-sectional regression analysis show that the heterogeneity of synchronization is partly accounted for by the progress in financial and trade openness. Also, the city-level analysis implies that the international synchronization is mainly driven by the city-level connectivity between large and international cities.
\end{abstract}

JEL Classification Numbers: C38, F36, G15

Keywords: Housing price, Dynamic factor model, Financial openness

Author’s E-Mail Address: mkatagiri@imf.org

\footnotetext{
* The views expressed here are those of the author and do not necessarily represent the views of the IMF, its Executive Board, or IMF management. The author thanks staff of IMF for valuable comments.
} 
Contents

Abstract

I. Introduction $\underline{4}$

II. Econometric Specification and Data

A. A Dynamic Factor Model and Synchronization Measure

B. Data

III. Estimation Results $\underline{10}$

A. Developments in Synchronization of House Prices

B. What Drives the Synchronization of House Prices?

IV. Concluding Remarks

TABLES

1. Estimation Result for the Panel Regression $\underline{27}$

2. Estimation Results for the Cross Sectional Regression

FIGURES

1. Individual House Price Growth and the Global Factor 21

2. Developments in Synchronization of House Prices

3. Synchronization of House Prices by Country (1971: Q1-) __ 22

4. Contribution of Global Factor in House Price Growth $\underline{\underline{22}}$

5. Synchronization of House Prices by Country (2002: Q1-) $\underline{23}$

6. Contribution of Global and Regional Factors in Asian House Price Growth

7. Global Factor for the City-Level Data and the Country-Level Data 23

8. Contribution of Global and Regional Factors in Selected Cities 24

9. House Price Synchronization and Financial Openness

$\frac{25}{26}$

APPENDIX

1. Data Sources and Country Coverage $\underline{20}$

References $\underline{18}$ 


\section{INTRODUCTION}

House price dynamics are tightly connected with macroeconomic performance via various channels. ${ }^{1}$ For instance, in housing booms, households possibly take excessive risks in borrowing supported by increasing house prices, but in the face of ensuing housing price collapse, they could face a tighter budget constraint due to the underwater mortgages caused by declines in house prices, forcing them to substantially reduce their consumption (Mian and Sufi, 2009). Such a risk to macro-financial stability through the housing cycle has been a concern for policymakers for a long time, but if each country's housing prices were isolated with each other, such a risk would be contained in a given country and so policymakers in other countries would not need to be concerned about it. However, if housing prices were synchronized across countries, a risk to macro-financial stability through the housing cycle in one country could be amplified and transmitted to another country, thus possibly causing macro-financial instability on a global scale. Hence, investigating the developments in house price synchronization and its driving force is an important policy issue in monitoring a risk to macro-financial stability.

This paper investigates the cross-country synchronization of house prices and its drivers. Following the literature of dynamic factor models, the paper estimates a dynamic factor model that assumes that house price growth in each country consists of a global factor, a regional factor, and an idiosyncratic country-specific factor. As in the previous literature, the global factor is common across all countries while the regional factor, which is extracted from the residual of the global factor, is common across countries only in a particular region. Then, the share of variance explained by the common global factor is used as a proxy for the degree of house price synchronization for each country. Since this methodology provides the degree of house price synchronization by country, its cross-country variation can be used for identifying the drivers of house price synchronization by linking it to country-specific variables such as financial openness and trade openness. Furthermore, by computing the degree of house price synchronization with rolling windows, we can examine the developments in aggregate (and individual country's) degree of house price synchronization over time and use the time-series variation for identifying the driver of synchronization in a panel regression.

In theory, house prices across countries are synchronized by various channels. First, house prices are synchronized just reflecting synchronization of real economic activity. House prices are influenced by real economic variables including consumption, income, output, etc. in each country because those real economic variables affect households' demand for housing. Hence, if real economic activity is synchronized across countries, particularly through the import and export linkages, house prices across countries will be also synchronized reflecting the real econoimc synchronization. Second, house prices can be

\footnotetext{
${ }^{1}$ See, for example, Claessens et al. (2011) for an extensive empirical analysis on this issue.
} 
synchronized due to simultaneous changes in financial factors. For instance, the global financial condition and investors' expectation for its future developments would simulaneously affect house prices in many countries, thus leading to synchronization of house prices across countries. Also, if global investors can access to housing makets in many countries at the same time, house prices in those countries would move in tandem as a result of the global investors' portfolio choice. If financial factors play an important role for synchronization of house prices, financial openness for each country would independently influence the degree of house price synchoronization, separately from the synchronization induced by real economic connectivity through trade linkages.

The main empirical results of this paper are as follows. First, the empirical results using the house price data for 19 countries, where the long timeseries data are available, show that the degree of house price synchronization across countries has been rising since the 1970s. The developments in synchronization measure across countries show that while the share of variance explained by the commom global factor is only around 10 percent in the $1980 \mathrm{~s}$ on average, it has increased and reached around 40 percent in 2016, suggesting that house prices across countries have been more and more syncronized over time. Second, a cross-sectional and panel regression analysis show that the degree of synchronization is partly accounted for by financial openness. While the degree of house price synchronization has been gradually increasing on average, it is shown that there is also a large heterogeneity across countries in the degree of synchronization. To understand what drives the heterogeneity of synchronization across countries, this paper conducts (i) a cross-sectional regression using a broader sample of countries with shorter sample periods, and (ii) a panel regression using a smaller sample of countries with longer sample periods, and both of them point out statistically significant effects of financial openness, proxied by the Chinn-Ito index (Chinn and Ito, 2006), on the degree of house price synchronization, even after controlling for the real economic connectivity captured by gross trade volume to GDP ratios. Third, the same analysis using the city-level data shows that, in some countries, the global factor has significant effects on house prices only in large and international cities, implying that the international synchronization of house prices may be driven by the city-level connectivity between large and international cities rather than the country-level connectivity.

Those empirical results in this paper have some policy implications. First, given the increasing synchronization of house prices across countries, house prices need to be monitored from more global perspectives. That is, when policymakers monitor their own country's house prices as a part of economic assessment, they should pay attention not only to the economic factors influencing their own country's house prices but also the global cycles of house prices and their underlying factors. Second, the empirical results imply that house prices are projected to be more synchronized across countries in the future if more countries including emerging economies continue to become more financially open, and vice versa. Hence, while the world with greater financial openness has an advantage for providing, for instance, diversified investment opportunities, the spillover of shocks through 
house price synchronization will possibly pose a more significant risk to financial stability in the future.

In terms of literature, this paper is mainly related to two strands of empirical macroeconomics. First, this paper is based on the literature for macroeconomic applications of a dynamic factor model. A seminal paper in this literature is Kose et al. (2003), which investigate the business cycle synchronization across developed economies and explore the driver of synchronization by using the measure of synchronization based on variance decomposition. While many empirical papers use a dynamic factor model and their methodology to measure the synchronization (e.g., Kose et al 2008; IMF 2017), the most closely related study to the present paper among them is Del Negro and Otrok (2007). While they only focus on the U.S. data rather than cross country data, they apply a dynamic factor model to the state-level house price data and try to figure out a driving force of the common factor, particularly focusing on monetary policy. Second, this paper is also related to the literature on international correlation of asset prices. For instance, Forbes (2012) investigates the cross-country correlation of stock returns and documents the rise in correlation since the 1980s. Most papers in this literature, however, focus on stocks or other financial asset returns and few studies mention house price synchronization. Notable exceptions are Hirata et al. (2012) and IMF (2004). Both of them document the increasing trend in house price synchronization across countries and emphasize the global synchronicity of monetary policy as a driving force, but do not analyze the cross-country heterogeneity in the degree of synchronization. ${ }^{2}$

The rest of paper proceeds as follows. Section 2 explains the econometric specification for the dynamic factor model for house prices and the synchronization measures, and briefly describes the data for estimation. Section 3 estimates the dynamic factor model to examine the developments in synchronization of house prices and investigates what drives the synchronization by cross-country analyses. Concluding remarks are provided in Section 4.

\footnotetext{
${ }^{2}$ Actually, Hirata et al. (2012) raises the analysis on determinants of cross-country differences in the degree of synchronization as one of possible avenues for future research. In their conclusion, they note that "we do not articulate why house prices have become more synchronized over time. A natural next topic to explore is a deeper analysis of differential effects of shocks and structural features of countries, including their linkages through the banking system, on the temporal changes in the degree of synchronization of house prices."
} 


\section{ECONOMETRIC SPECIFICATION AND DATA}

This section first explains the econometric specification of the dynamic factor model for house prices. Then, the synchronization measure of house prices is defined, based on the global factor estimated by the dynamic factor model. Finally, the section briefly describes the country- and the city-level dataset used for estimation.

\section{A. A Dynamic Factor Model and Synchronization Measure}

To analyze the synchronization of house prices across countries, house price dynamics are decomposed into common and idiosyncratic factors by a dynamic factor model with timevarying parameters. In the model, quarterly growth of real house prices for country $i$ in period $t, h_{i, t}$, is assumed to consist of the global factor, $g_{t}$, the regional factor for region $k$, $r_{k, i}$, and the country-specific idiosyncratic component, $c_{i, t}$ :

$$
h_{i, t}=\lambda_{g, i, t} g_{t}+\lambda_{r, i, t} r_{k, t}+c_{i, t}
$$

where $\lambda_{g, i, t}$ and $\lambda_{r, i, t}$ are the time-varying factor loadings for the global and regional factor. All countries in the sample are categorized into one of three regions (Europe, Asia, and America), and house prices in the same region are assumed to share the same regional factor. In the estimation, the global and regional factor are extracted sequentially. That is, the global factor is extracted first, and then the regional factor for each region is extracted from the residuals after extracting the global factor. Hence, the global factor, $g_{t}$, is supposed to represent a common factor of house price dynamics across all countries, and the regional factor, $r_{k, t}$, is supposed to represent a common component of house prices only in the region, which is orthogonal to the global factor. The global (regional) factor is estimated by assuming that it follows a vector autoregression (VAR) jointly with global (regional) output, inflation, and interest rate. Specifically, let $X_{t} \equiv\left[f_{t}, Y_{t}\right]^{\prime}$ where $Y_{t}$ is a vector of the global (or regional) macroeconomic variables of interest and $f_{t}$ is a global or a regional factor, i.e., $f_{t}=$ $g_{t}$ or $f_{t}=r_{k, t}$. Then, the VAR is formulated as,

$$
X_{i, t}=\sum_{j=1}^{n} B_{j, t} X_{t-j}+\epsilon_{t}
$$

where $B_{j, t}$ is a vector of the time-varying parameters, which are estimated simultaneously with the factor loadings in the equation (1). The global (regional) macroeconomic variables in the VAR correspond to the first principal component that variable across the corresponding group of countries.

The global (regional) factor and the model parameters are simultaneously estimated by the following two-step approach. In the first step, the principal component of house price growth, output, inflation and short-term interest rates is extracted from the cross country data, and 
used for estimating the time-varying factor loadings and the variance-covariance matrix in the equation (1) as well as the parameters for the VAR in the equation (2). Then, in the second step, the global (or regional) factor is extracted by the Kalman smoother, given the time-varying factor loadings, the variance-covariance matrix, and the VAR parameters estimated in the first step. ${ }^{3}$

Based on the previous literature such as Kose et al. (2003) and Del Negro and Otrok (2007), synchronization of house prices for each country is measured by the relative importance of the global factor (and the regional factor). More specifically, the synchronization of house prices for country $i$ in period $t$ is measured by the share of variance explained by the variance of the global (and regional) factor:

$$
\operatorname{synch}_{L, i, t}=\frac{\operatorname{var}_{L}\left(\lambda_{i, t} g_{t}\right)+\operatorname{var}_{L}\left(\lambda_{r, i, t} r_{k, t}\right)}{\operatorname{var}_{L}\left(h_{i, t}\right)} \text { or } \operatorname{synch}_{L, i, t}=\frac{\operatorname{var}_{L}\left(\lambda_{i, t} g_{t}\right)}{\operatorname{var}_{L}\left(h_{i, t}\right)}
$$

where $\operatorname{var}_{L}(\cdot)$ is the realized variance from period $t-L$ to $t$. Since higher $\operatorname{synch}_{L, i, t}$ means that house price growth in country $i$ is more accounted for by a global (and regional) cycle of house prices within a fixed window $[t-L, t]$, it can be interpreted that house prices in country $i$ are more synchronized with other countries' house prices. Therefore, by looking at crosssectional differences in synch ${ }_{L, i, t}$ across countries, we can identify which country's house prices are more synchronized with the global housing cycle than others. Also, by estimating synch $_{L, i, t}$ by rolling windows (i.e., calculating $\operatorname{synch}_{L, i, t}$ in period $t=L+1, L+2 \ldots$ with a fixed value of $L$ ), we can examine the developments in synchronization of house prices for each country over time.

The synchronization measure, synch $_{L, i, t}$, varies across countries and over time mainly by the following two reasons. First, synch $h_{L, i, t}$ may become higher because the factor loading $\lambda_{i, t}$ becomes larger. This argument is intuitive because it means that when the country $i$ 's house price growth is more sensitive to the global housing cycle (i.e., a higher factor loading, $\lambda_{i, t}$ ), house prices in country $i$ are recognized as more synchronizing with others. Second, synch $_{L, i, t}$ may become higher because the relative variance of the country specific factor to the global factor, $\operatorname{var}\left(c_{i, t}\right) / \operatorname{var}\left(g_{t}\right)$, becomes smaller. It means that, even when the sensitivity to the global factor is unchanged, house prices in country $i$ could be more synchronized with the global cycle if the country specific factor became less fluctuating. I

\footnotetext{
${ }^{3}$ The two-step approach is econometrically less rigorous than the traditional approach, which simultaneously estimates factor loadings and the global (and regional) factors by a Bayesian method (e.g., Kose et al. 2003). The two-step approach is, however, much more tractable in practice and gives almost the same results as in the traditional approach for most cases. See Doz, Giannone, and Reichlin (2011) and Koop and Korobilis (2013) for more detailed discussion on the two-step approach to estimate a dynamic factor model. The estimation by the two-step approach in this paper is conducted by modifying the Matlab programs available at Dimitris Korobilis' webpage (https://sites.google.com/site/dimitriskorobilis/matlab).
} 
will return to the distinction between the two underlying reasons for changing the degree of synchronization when investigating a driving force of synchronization. ${ }^{4}$

\section{B. Data}

The analysis uses cross-country data of real house prices (house prices deflated by consumer prices) for 27 countries from the 1970s. ${ }^{5}$ Since the availability of house price data is different by country, the following two datasets are compiled for the empirical analysis. The first dataset is the one for short periods but covering many countries ("the short dataset," hereafter). The short dataset starts at 2002: Q1 and so contains only around 60 periods, but covers 27 countries including many emerging economies. The second dataset, on the other hand, is the one containing the data for extended periods but covering a small number of countries ("the long dataset," hereafter). The long dataset starts at 1971: Q1 but covers only 19 countries, most of which are advanced economies. In what follows, the short dataset will be used mainly for identifying the cross-sectional heterogeneity among countries while the long dataset will be used for analyzing the developments in synchronization over time, including a panel regression to investigate a driving force of synchronization.

The analysis also uses the city-level data to complement the country-level analysis. The city-level dataset for real house prices starts at 2002: Q1 and covers 224 cities in advanced and emerging economies. While the city-level data provide more granular information on house prices, it is worth noting that the number and size of cities in the sample are very different from country to country. For instance, the city-level data for China give house prices in more than 30 cities including rural ones, those for France give house prices only for 8 cities mainly around Paris. Hence, the city-level data are not suitable for discussing the synchronization of house prices across cities in different countries. ${ }^{6}$ Rather, the city-level analysis should focus on comparing cities in the same country to obtain some information complementary to the country-level analysis, particularly information about the underlying forces for house price synchronization.

\footnotetext{
${ }^{4}$ For more formal discussion to distinguish between those two cases in a simple theoretical framework, please see Doyle and Faust (2005) and Technical Annex in IMF (2018).

${ }^{5}$ See Annex 1 for the list of countries covered by the dataset.

${ }^{6}$ For instance, even if we had the result that house prices in French cities are more synchronized with the global trend compared with Chinese cities, such a result could be induced by the fact that the sample for French cities contain only large cities, and so it could not necessarily mean that French cities in general are more exposed to the global trend than Chinese cities.
} 


\section{ESTIMATION RESULTS}

The empirical analysis consists of two parts. First, based on the estimated dynamic factor model by cross-country data, I describe the developments in synchronization of house prices over time and its heterogeneity across countries. Then, in the second part, driving forces of house price synchronization are investigated by a cross sectional regression and a panel regression, particularly focusing on financial openness as a key driver.

\section{A. Developments in Synchronization of House Prices}

The estimated global factor points to the existence of the global housing cycle. Figure 1 shows the global factor of house price growth (the solid blue line) along with each country's house price growth (the thin black lines), estimated by the long dataset from 1970: Q1. The figure shows that even though individual country's house price growth contains very volatile idiosyncratic components, the estimated global factor captures a smooth and cyclical common factor across them. Also, the dashed red line in Figure 1 shows the global factor estimated by the short dataset from 2002: Q1. It indicates that the global factors identified by the two datasets with different country coverage are almost identical, suggesting that the estimation of global factor is relatively robust to the sample periods and the country coverage.

The synchronization measure based on the dynamic factor model implies that the synchronization of house prices across countries has been increasing on average since the 1970s. In this analysis, the synchronization measure, $s_{n n c h} h_{i, t, L}$, is calculated by the second formula in the equation (3), which is based on only the global factor and its time-varying factor loading. ${ }^{7}$ Figure 2 shows the median, 25-percentile and 75-percentile of synchronization measure for the 15-,20- and 25-year window (i.e., $L=60$, 80, and 100 for quarterly data). The figure points to a clear upward trend for all windows, suggesting that house prices in the world has been more and more synchronized over time. For instance, while the median of synchronization measure for the 15-year window was just around 10 percent in the mid-1980s, it has increased and reached around 35 percent in 2016, meaning that around 35 percent of variance in house price growth across countries can be on average accounted for by one common global factor.

The estimated synchronization measure also implies that there is a substantial heterogeneity across countries in the degree of house price synchronization. While Figure 2 indicates that the synchronization has been increasing on average, the large 25- and 75-percentile bands in the figure (the dashed lines around the median values) implies that a large heterogeneity exists across countries. To see more details on the heterogeneity across countries, Figure 3 shows the $s y n c h_{i, t, L}$ by country calculated for the entire sample periods of the long dataset

\footnotetext{
${ }^{7}$ In the estimation using the long dataset, the regional factor is not included in the estimation because the sample countries are dominated by European countries and there is not sufficient regional diversity.
} 
from 1971: Q1. The figure indicates that the importance of the global factor (i.e., the variance of house price growth explained by the global factor) ranges from almost zero percent for DEU and ITA to around 60 percent for GBR, implying a substantial heterogeneity across countries in the degree of synchronization. Also, Figure 4 illustrates the global factor multiplied by the factor loading (i.e., $\lambda_{g, i, t} g_{t}$, the red lines) along with the developments in house prices for some selected countries. The figure shows that while house price growth in GBR has been mostly explained by the global cycle of house prices, those in AUS and CAN contain substantial idiosyncratic components, and that house price growth in ZAF and NLD have been slightly influenced by the global cycle but mostly driven by country-specific idiosyncratic factors. In the following subsection, I will investigate what drives the heterogeneity across countries by a panel regression.

The heterogeneity in the degree of house price synchronization is also observed between advanced and emerging economies as well as between regions. Since the long dataset, which is used for the analyses up to here, contains almost only advanced economies, it does not tell anything about the heterogeneity between advanced and emerging economies as well as the heterogeneity across regions. To complement this shortcoming of the analysis using the long dataset, the same analysis is conducted by the short dataset covering more countries including emerging economies. In the analysis using the short dataset, the synchronization measure, synch ${ }_{i, t, L}$, is calculated by the whole sample periods rather than by a rolling estimation with the fixed window (i.e., $L$ is equal to the length of the whole sample periods), given its fairly short sample periods. The main empirical results using the short dataset are as follows. First, the estimated synchronization measure indicates that house prices in advanced economies are much more synchronized with the global cycle than those in emerging economies are. Namely, the average synch $_{i}$ for advanced economies is $30-40$ percent while that for emerging economies is less than 10 percent, suggesting that the heterogeneity in the degree of house price synchronization would be much larger between advanced and emerging economies than the heterogeneity only among advance economies. Second, the analysis also points out that the degree of house price synchronization is substantially different by region. In Figure 5, the estimated contribution of the global factor, $\frac{\operatorname{var}_{L}\left(\lambda_{i, t} g_{t}\right)}{\operatorname{var}_{L}\left(h_{i, t}\right)}$, is shown as the dark blue bar, and the estimated contribution of the regional factor, $\frac{\operatorname{var}_{L}\left(\lambda_{r, i, t} r_{k, t}\right)}{\operatorname{var}_{L}\left(h_{i, t}\right)}$, is shown as the light blue bar (Europe), the green bar (Asia), and the yellow bar (North and South America), respectively. ${ }^{8}$ The figure indicates that the global factor's contribution is much higher in Europe and North and South America than in Asia (the average contribution of the global factor is around 20 percent in Europe and America while it is only around 10 percent in Asia). Interestingly, however, once the contribution of the

\footnotetext{
${ }^{8}$ In the analysis using the short dataset, the Euro area is included in the sample and countries in the Euro area are dropped from the sample. Otherwise, the sample is dominated by too many European countries. The main conclusion is, however, almost unchanged even if we use individual country's data rather than the Euro area data.
} 
regional factor is taken into account, the average $\operatorname{synch}_{i}$ in Asia is not substantially lower than other areas, implying that Asian countries are synchronized only among Asian countries. To see the relative importance of regional factor in Asia, Figure 6 shows the developments in house prices for selected Asian countries along with the global and regional factor multiplied by the factor loading (i.e., $\lambda_{g, i, t} g_{t}$ and $\lambda_{k, i, t} r_{k, t}$; the red and green lines in the figure). The figure indicates that the regional factors play an important role for explaining the volatility of house price growth in Asian countries: While the global factors, the red lines, are almost negligible in all countries other than AUS, the regional factors, the green lines, explain a large part of house price variations in many countries.

Finally, to complement the country-level analysis, the same analysis on synchronization of house prices is conducted for the city-level data. While the previous section explains econometric specifications only for the country-level analysis, the specifications for the citylevel analysis is analogous to that for the country-level analysis. In the city-level analysis, house price growth in city $i, h_{i, t}$, is assumed to consist of the global factor, $g_{t}$, the country factor for the country to which the city $i$ belongs, $r_{k, i}$, and the city-specific idiosyncratic component, $c_{i, t}$. As in the country-level analysis, the global factor is shared by all cities in the sample while the country factor is shared only by cities located in the country. Then, those global and country factors are extracted by the two-step procedure as in the countrylevel analysis. Figure 7 shows the developments in the global factor extracted from the citylevel data (the blue solid line) along with the global factor extracted by the country-level data (the red dashed line). The figure indicates that the developments in those factors are very close, suggesting that the country-level data and city-level data are driven by almost the same common factor in a dynamic factor model.

The city-level analysis implies that, in some countries, the international synchronization of house prices may be a city-level phenomenon rather than a country-level one. Figure 8 shows the developments in house prices for a few large cities in KOR, CAN, USA, and CHN, along with the global and country factor multiplied by the factor loadings (i.e., $\lambda_{g, i, t} g_{t}$ and $\lambda_{k, i, t} r_{k, t}$; the red and green solid lines in the figure). The charts in Figure 8 imply that there are substantial differences in the degree of synchronization across cities even within the same country. For instance, the charts for KOR and CAN (the first and second row in Figure 8) indicate that the global factor (the red line) explains a substantial portion of house price variations only in Seoul and Vancouver (and Montreal). Also, the charts for USA (the third row in Figure 8) indicate that while the global factor significantly affects house price growth in large and international cities such as New York, Los Angeles, and Chicago, it has much smaller effects in Dallas. The charts for China (the last row in Figure 8) show, however, that even in large cities such as Beijing and Shanghai, their house prices are barely exposed to the global factor, suggesting that the degree of synchronization is not only determined by the size of city but also other aspects. Finally, all charts in Figure 8 indicate that while the global factor is almost negligible in many cities, the country factor (the green line), which is 
orthogonal to the global factor by definition, has a considerable influence in almost all cities in all countries.

In sum, the city-level analysis suggests that the rise in international synchronization of house prices may be driven by a city-level connectivity only among large and international cities rather than a country-level connectivity. It is intuitive because if the international synchronization of house prices is driven by, for instance, investment flows by global investors, the synchronization of house prices would be observed only in large and international cities where global investors tend to invest. The result of the city-level analysis is intuitive and suggestive, but it may be good to consider it as just complementary to the country-level analysis due to the following caveats. First, since there are large gaps in availability of the city-level data from country to country, it is difficult to examine whether the above finding is observed globally or only in a limited number of countries. Therefore, it is difficult to provide quantitative results of the city-level analysis in a global basis beyond looking at some country case studies in Figure 8. Second and relatedly, it is not straightforward how to reconcile the city-level analysis with the country-level analysis. In particular, the city-level analysis shows that the global factor is almost negligible in most small cities, but this result seems to contradict the country-level analysis, which shows that a substantial part of variance of the country-level house prices is explained by the global factor. ${ }^{9}$ Hence, more quantitative analyses at the city level are necessary to resolve those issues, but we need more comparable and comprehensive city-level data for more countries.

\section{B. What Drives the Synchronization of House Prices?}

This subsection investigates what are the key drivers of house price synchronization across countries. More specifically, this subsection asks what explains (i) the upward trend in the house price synchronization on aggregate, and (ii) the large heterogeneity in the degree of synchronization across countries, both of which are identified in the previous subsection. To answer this question, this subsection provides empirical analyses, namely a cross-sectional regression using the short dataset and a panel regression using the long dataset, particularly focusing on the role of financial and trade openness.

\footnotetext{
${ }^{9}$ While we do not have city-level data granular enough to explore this issue, there are some possibilities to reconcile those findings. First, if the city specific idiosyncratic factors are independent with each other, they are expected to wash out in the aggregate. Thus, the country level house prices are expected to be mainly driven by common factors across cities, including the global factor and the country factor. Second, when making the country level house prices, the weight for large cities may be larger than others. Thus, the country level house prices are highly correlated with large cities' house prices compared with small cities' house prices.
} 
First, the relationship between the house price synchronization and financial/trade openness is analyzed by a panel regression. In this analysis, we run the regression:

$$
\text { synch }_{L, i, t}=\alpha_{i}+\delta_{t}+\beta_{1} \text { kaopen }_{i, t}+\beta_{2} \operatorname{tr}_{i, t}+\gamma Z_{i, t}
$$

where $\alpha_{i}$ is a country fixed effect. Here, $\operatorname{synch}_{L, i, t}$ is computed by the dynamic factor model estimated by the long dataset starting 1971Q1. For the length of the fixed window to calculate $s y n c h_{L, i, t}$, we use the three values, $L=60,80$, and 100 (i.e., 15 years, 20 years, and 25 years). Financial openness is measured by capital account openness proxied by the Chinn-Ito index (Chinn and Ito, 2006), kaopen $_{i, t}$, and trade openness is measured by ratios of gross trade volume (i.e., gross value of imports plus exports) to GDP, $t r_{i . t} \cdot{ }^{10}$ As a measure of financial and trade openness during the fixed window $[t-L, t]$, we use the weighted average, $\frac{1}{\sum_{l=0}^{L}(l+1)} \sum_{l=0}^{L-1}(l+1) x_{i, t-l}$ for $x_{i, t}=$ kaopen $_{i, t}$ and for $x_{i, t}=t r_{i, t}$. The weighted average put more weights on periods close the beginning of the window. The rationale for using this type of weighted average is that the financial and trade openness may take some time to have effects on synchronization of house prices, thus making the early periods in the window more relevant for the synchronization within the window. Finally, time dummies, $\delta_{t}$, and a vector of control variables, $Z_{i, t}$, including the log of real GDP and CPI inflation are incorporated into the regression. Adding time dummies is important in this panel regression because both synch ${ }_{L, i, t}$ and most explanatory variables are slow moving variables and possibly include non-stationary components.

The estimation results for the panel regression (Table 1) show that the degree of house price synchronization is significantly influenced by financial and trade openness. For all windows of variance decomposition ( $L=15$ years, 20 years, and 25 years), the coefficients for financial openness and trade openness are positive and statistically significant. Since the panel regression contains the fixed effect for each country, the estimation result in Table 1 is interpreted that the significant heterogeneity across countries in terms of rises (or declines) in the synchronization of house prices since the 1970s is partly accounted for by the differences in the progress of financial and trade openness during the same periods. For instance, while the countries like USA and DEU have experienced little changes in both financial openness and the degree of house price synchronization during the sample periods (because those countries were financially open even in the 1970s), some European countries like ITA and ESP have experienced significant increases in both financial openness and the degree of

\footnotetext{
10 The Chinn-Ito index is constructed by de-jure financial openness in the IMF indexes (See Chinn and Ito (2006) for more details about the methodology to construct the index). Hence, the literature often uses gross foreign asset and liability as a proxy for de-facto financial openness, but such a proxy for de-facto financial openness does not have any significant effects on house price synchronization in this paper's framework (The estimation results are not shown in the main text). This is probably because the amount of foreign asset and liability is driven by not only financial openness but also other factors including economic developments etc.
} 
house price synchronization, thus leading to the positive correlation between them. Also, the fact that both financial and trade openness have statistically significant effects on synchronizations suggests that financial openness is a relevant factor even after controlling for the real economic connectivity captured by gross trade volume. Hence, the estimation results imply that financial factors such as investment flows by global investors play an important role in explaining the increase in house price synchronization, separately from those induced by real economic connectivity through trade linkages across countries.

The second columns of each window in Table 1 indicate that the significant effects of financial and trade openness on the degree of house price synchronization still exist even after controlling for changes in variance of the country-specific factor, $c_{i, t}$. This exercise is an important robustness check because, as is mentioned earlier, synch $_{L, i, t}$ rises not only when the sensitivity of house prices to the global factor increases but also when variance of the country-specific factor becomes smaller relative to variance of the global factor. The estimation results in Table 1 show that the financial and trade openness are still positive and statistically significant for $L=20$ years or 25 years, suggesting that financial and trade openness significantly influence the long-term synchronization of house price mainly through the rise in sensitivity of house prices to the global factor. For the short-term synchronization (i.e., $L=15$ years), on the other hand, financial openness loses its significance, and instead, the variance of the country-specific factor, $c_{i, t}$, has negative and statistically significant effects on the synchronization of house prices. This result can be interpreted that (temporal) changes in variance of the country-specific factors significantly influence the synchronization of house prices within the short window and thus wipe out the long-term effects of financial openness on synchronization.

Next, we run the cross-sectional regression to assess the effects of financial and trade openness on the degree of house price synchronization in a broader sample of countries including emerging economies. A caveat for the above panel regression is that the synchronization measure is calculated by the long dataset from 1971Q1 to secure sufficiently long periods of sample for conducting a panel regression, and thus the sample contains almost only advanced economies, mainly European countries. Hence, it is still unclear whether the above estimation results pointing to the significant effects of financial and trade openness are satisfied in a broader sample of countries. To clear this concern about the panel regression covering only advanced economies, we use $s y n c h_{L, i}$ based on the dynamic factor model estimated by the short dataset from 2002Q1 covering 27 countries including emerging economies, and run the cross-sectional regression:

$$
\text { synch }_{i}=\alpha+\beta_{1} \text { kaopen }_{i}+\beta_{2} \text { tr }_{i}
$$

Here, kaopen $_{i, t}$ and tr.t $_{i . t}$ are the financial and trade openness measured by the Chinn-Ito index and the ratios of gross trade volume to GDP, respectively. In the regression, synch $_{L, i}$ is 
computed for the entire sample periods since 2002Q1, and the simple average of kaopen $_{i, t}$ and $t r_{i . t}$ during the sample periods is used for the estimation.

The cross-sectional regression using a broader sample of countries also points to significant and positive effects of financial openness on house price synchronization. Figure 9 illustrates the scatter plots of $\operatorname{synch}_{i}$ against financial openness. The left chart uses only the global factor for computing synch $i$ while the right chart uses both the global and regional factor for computing synch $_{i}$. Those charts show that there is a clear positive relationship between them, implying that more financially open countries, mainly shown in the right-edge of the figures as a perfectly open country, are associated with more synchronization of house prices. Table 2 provides more formal empirical results for the cross-sectional regression specified in the equation (4). The estimation uses the two types of $\operatorname{synch}_{i}$ defined in the equation (3), one is based on only the global factor and the other is based on both the global and regional factor, as in Figure 9. The estimation results indicate that financial openness has positive and statistically significant effects on house price synchronization for both types of $\operatorname{synch}_{i}$, while trade openness does not have a significant effect, suggesting that financial factors still play a key role to determine the degree of house price synchronization even in a broader sample of countries including emerging economies. When the dummy variable for advanced economies are added to the estimation as a robustness check, the coefficient on financial openness loses its statistical significance because financially open countries are mostly advance economies, but still have statistically significant effects for the case with the global and regional factor. ${ }^{11}$

\section{CONCLUding ReMARKS}

This paper investigates the developments in house price synchronization across countries and tries to figure out what drives the synchronization by a dynamic factor model. A country- and city-level dataset is used for decomposing house price movements into a common global factor and others, and the variance of house prices explained by the global factor is used for a synchronization measure. The empirical results indicate that: (i) the degree of synchronization has been rising since the 1970s, and (ii) a large heterogeneity across countries in the degree of synchronization exists. Furthermore, the city-level analysis implies that the international synchronization of house prices may be driven by the city-level connectivity between large and international cities rather than the country-level connectivity. Finally, a panel and cross-sectional regression analysis show that the heterogeneity of house price synchronization across countries is partly accounted for by both financial and trade

\footnotetext{
${ }^{11}$ When output growth and inflation are added as control variables, all the statistical significance is lost for both

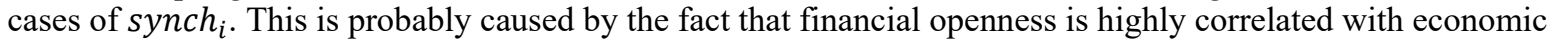
developments, and that the cross-sectional regression cannot identify the effects of financial openness orthogonal to economic developments, given the limited sample size in this analysis.
} 
openness, implying that financial factors influence the synchronization even after controlling for the real economic connectivity captured by trade linkages.

There are some directions for analytical works to complement the analyses in this paper. First, we need a structural macroeconomic model to understand why house price synchronization rises when the economy is associated with greater financial and trade openness. It is not a straightforward question theoretically because more openness may dampen rather than increase the synchronization. ${ }^{12}$ Second, the effects of house price synchronization on real economic activity is an interesting topic to examine. In particular, policymakers may be concerned whether higher synchronization of house prices implies a higher tail risk for economic growth. Third, the relationship between macroprudential policies and house price synchronization is an interesting policy issue, particularly whether the effectiveness of macroprudential policies depend on the prevailing degree of house price synchronization. While IMF (2018) provides comprehensive analyses for those topics, there is still plenty of room for deepening our understating for those issues.

\footnotetext{
${ }^{12}$ For instance, in a financially integrated world, global investors can continue to sell housing assets in countries associated with lower expected returns and buy housing assets in other countries, until the expected returns across countries converge to the same level. Such substitution effects can simultaneously lead to a collapse of housing prices in some countries and a surge of housing prices in other countries, thus damping the synchronization of house prices across countries. See Kalemli-Ozcan et al. (2013) for an analogous discussion for business cycle synchronicity.
} 


\section{References}

Chinn, Menzie D., and Hiro Ito. 2006. "What Matters for Financial Development? Capital Controls, Institutions, and Interactions." Journal of Development Economics 81 (1): 163-92.

Claessens, Stijn, M. Ayhan Kose, and Marco E. Terrones. 2011. "How Do Business and Financial Cycles Interact?” IMF Working Paper 11/88, International Monetary Fund, Washington, DC.

Del Negro, Marco, and Christopher Otrok. 2007. "99 Luftballons: Monetary Policy and the Housing Price Boom across U.S. States.” Journal of Monetary Economics 54 (7): 1962-85.

Doz, Catherine, Domenico Giannone, and Lucrezia Reichlin, 2011. “A Two-step Estimator for Large Approximate Dynamic Factor Models Based on Kalman Filtering," Journal of Econometrics, 164 (1), 188-205.

Doyle, Brian, and Jon Faust. 2005. "Breaks in the Variability and Comovement of G-7 Economic Growth." Review of Economics and Statistics 87: 721-40.

Forbes, Kristin. 2012. “The 'Big C': Identifying Contagion.” NBER Working Paper 18465, National Bureau of Economic Research, Cambridge, MA.

Hirata, Hideaki, M. Ayhan Kose, Christopher Otrok, and Marco E. Terrones. 2012. "Global House Price Fluctuations: Synchronization and Determinants.” NBER Working Paper 18362, National Bureau of Economic Research, Cambridge, MA.

International Monetary Fund (IMF). 2004. "Three Current Policy Issues." Chapter 2 in World Economic Outlook, September, Washington, DC.

_. 2017. "Are Countries Losing Control of Domestic Financial Conditions?” Chapter 3 in Global Financial Stability Report, April, Washington, DC.

—. 2018. "House Price Synchronization: What Role for Financial Factors?" Chapter 3 in Global Financial Stability Report, April, Washington, DC.

Kalemli-Ozcan, Sebnem, Elias Papaioannou, and Jose-Luis Peydro. 2013. "Financial Regulatin, Financial Globalization, and the Synchronization of Economic Activity" Journal of Finance LXVIII No. 3: 1179-1228.

Koop, Gary, and Dimitris Korobilis. 2013. “A New Index of Financial Conditions.” Working Paper. 
Kose, M. Ayhan, Christopher Otrok, and Eswar Prasad. 2012. "Global Business Cycles: Convergence or Decoupling?” International Economic Review 53 (2): 511-38.

Kose, M. Ayhan, Christopher Otrok, and Charles H. Whiteman. 2003. "International Business Cycles: World, Region, and Country-Specific Factors" American Economic Review 93 (4): 1216-1239.

Mian, Atif, and Amir Sufi. 2009. "The Consequences of Mortgage Credit Expansion: Evidence from the US Mortgage Default Crisis." Quarterly Journal of Economics 124 (4): 1449-96. 


\section{Appendix 1. Data Sources and Country Coverage}

Data sources: The data for house prices are residential property prices (seasonally adjusted) at country level (also at city level) deflated by CPI inflation in each country. They are compiled by the data form multiple sources including Bank for International Settlements; CEIC Data Co. Ltd; Emerging Markets Economic Data Ltd; Global Financial Data Solutions; Global Property Guide; Haver Analytics; IMF, Research Department house price data set; Organisation for Economic Co-operation and Development; Thomson Reuters Datastream; IMF staff calculation.

Country Coverage: The country coverage for country-level data is different for the long dataset from 1971Q1 and the short dataset from 2002Q1, due to the avialability of data by country. The long dataset covers only 19 countries including AUS, BEL, CAN, CHE, DEU, DNK, ESP, FIN, FRA, GBR, IRL, ITA, JPN, NLD, NOR, NZL, SWE, USA, ZAF while the short dataset covers 27 countries and area including AUS, CAN, CHE, CHL, CHN, COL, CZE, DNK, Euro Area, GBR, HKG, HUN, IDN, ISR, JPN, KOR, MYS, NOR, NZL, RUS, SGP, SRB, SWE, THA, TWN, USA, ZAF. Please note that the short dataset does not use individual data for European countries in the euro area but treat them as a one country. 
Figure 1. Individual House Price Growth and the Global Factor

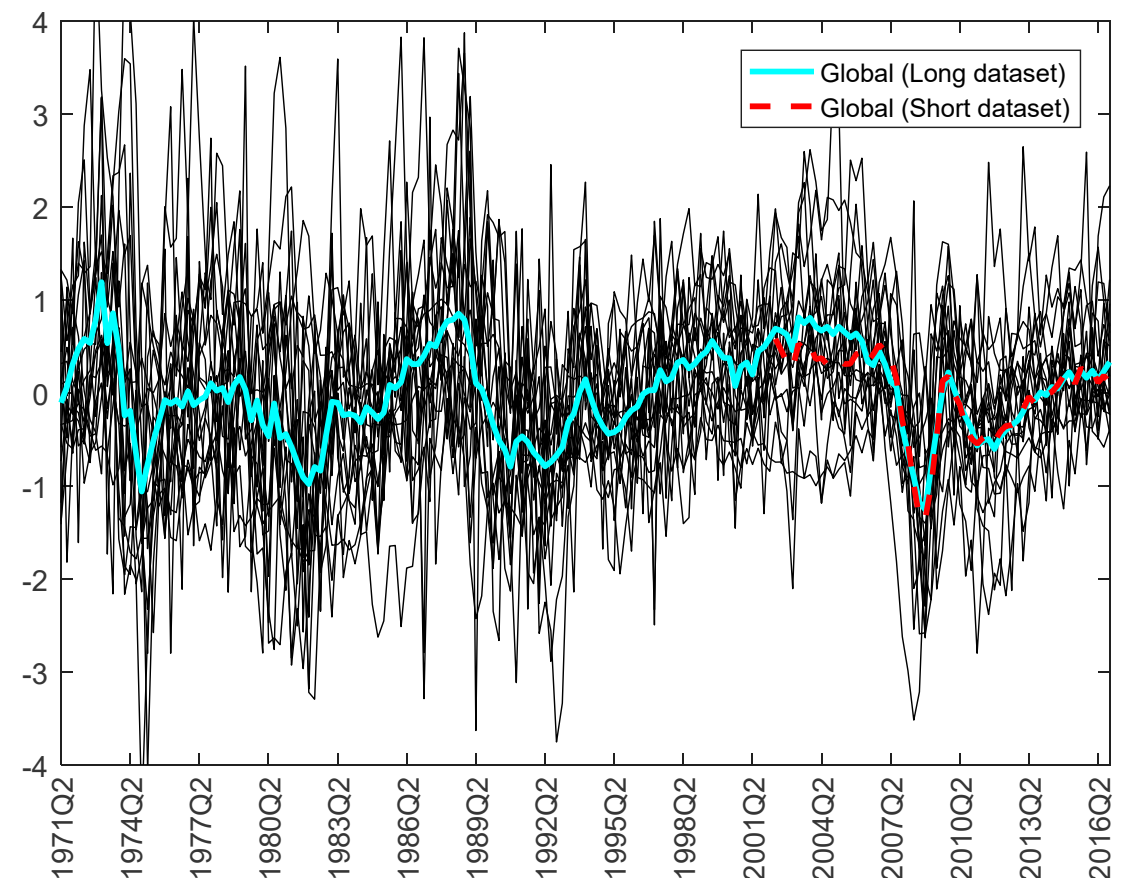

Source: See Appendix

Note: The black thin lines show $\mathrm{Q} / \mathrm{Q}$ real house price growth in each country. The light blue line and the dashed red line show the global factor extracted from the long dataset (1971: Q1-) and the short dataset (2002: Q1-).

Figure 2. Developments in Synchronization of House Prices
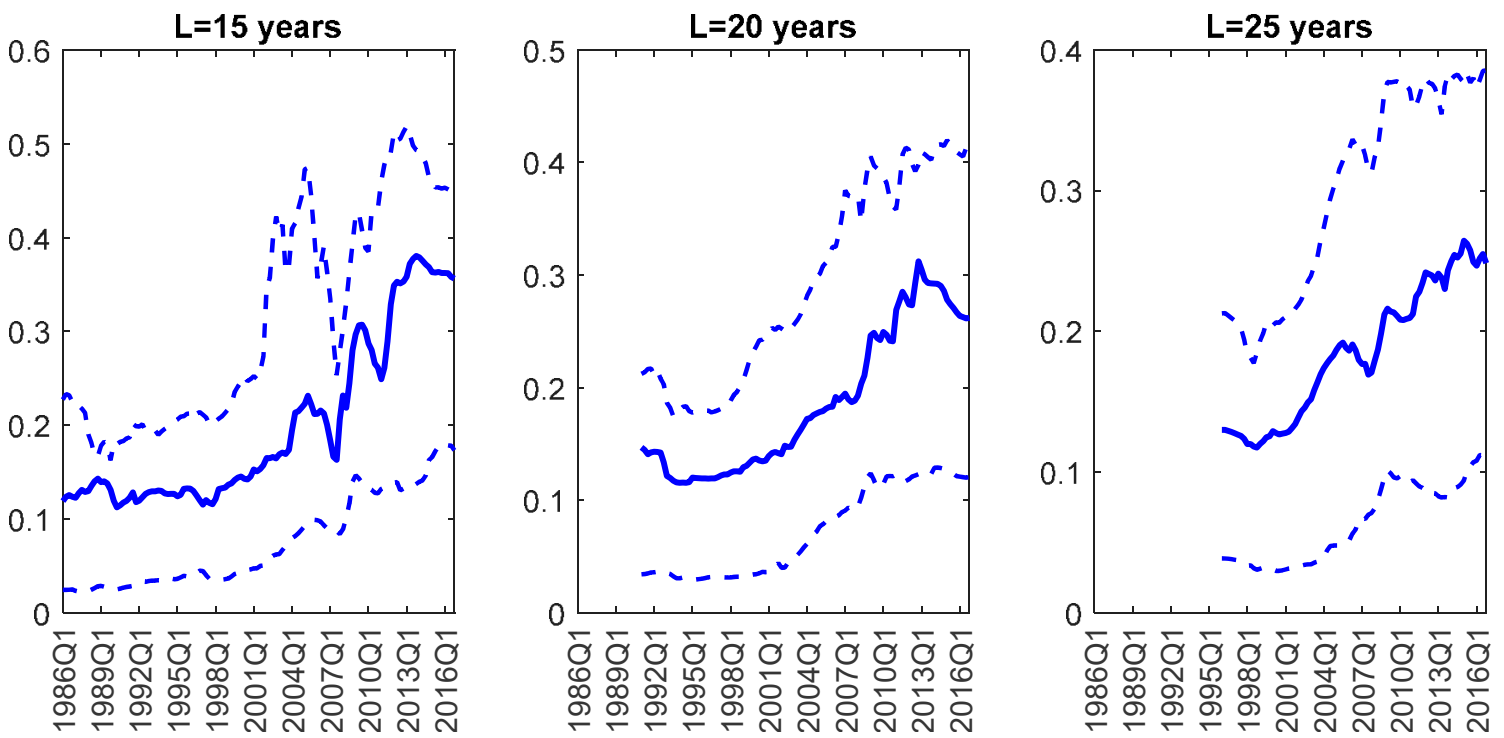

Source: See Appendix

Note: The charts show the 25-percentile, median, and 75-percentile of synchronization measures, defined in the equation (3) using only the global factor for the case of 15-year, 20-year, and 25-year window. 
Figure 3. Synchronization of House Prices by Country (1971: Q1-)

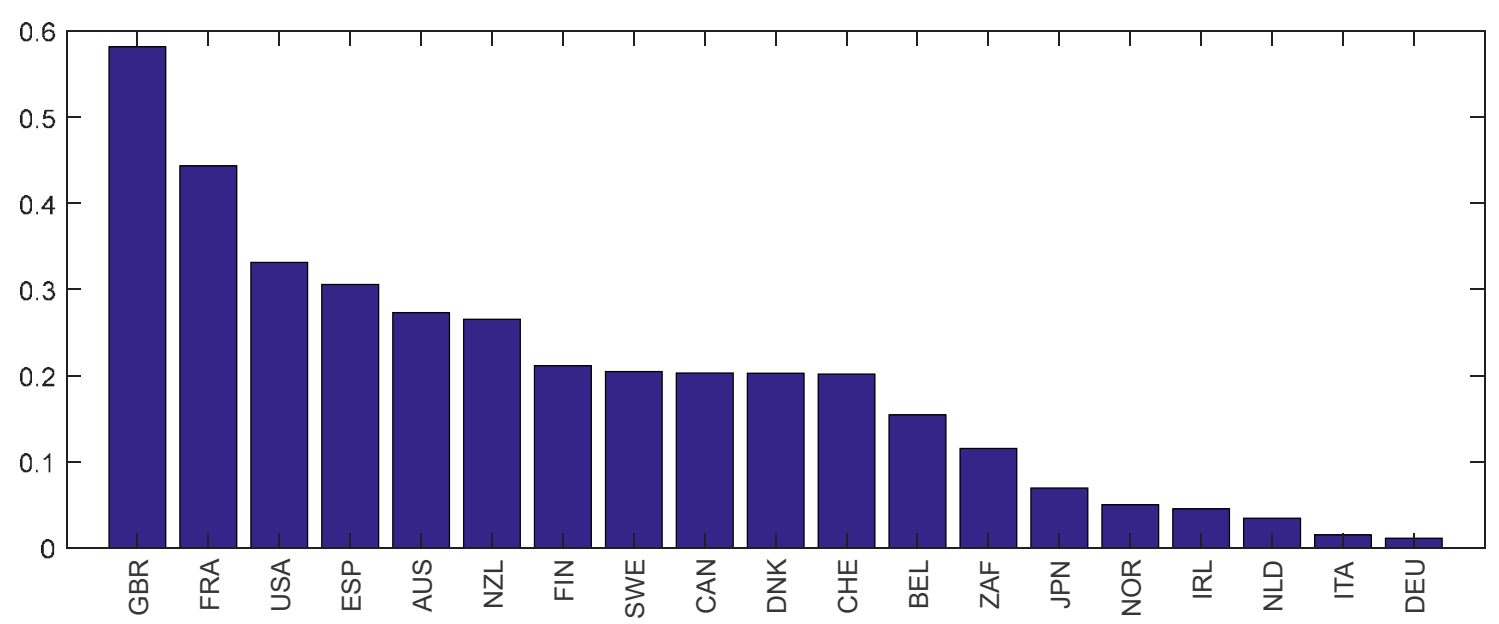

Source: See Appendix

Note: The figure shows the synchronization measure defined in the equation (3) by country. Those measures are computed by the whole sample periods.

Figure 4. Contribution of Global Factor in House Price Growth
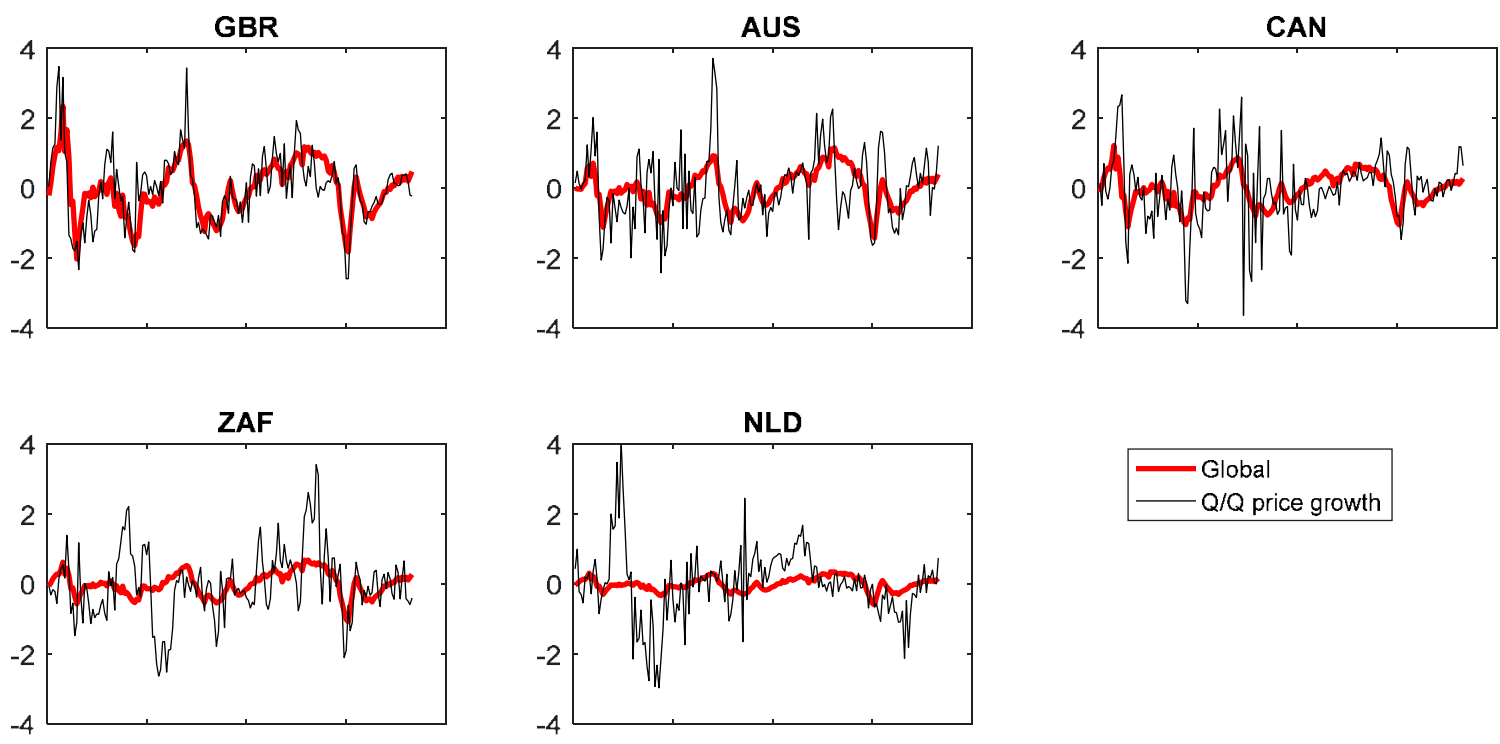

Source: See Appendix

Note: The charts show the global factor multiplied by the factor loading (i.e., $\lambda_{g, i, t} g_{t}$; the red lines) along with the developments in house prices for some selected countries. 


\section{Figure 5. Synchronization of House Prices by Country (2002: Q1-)}

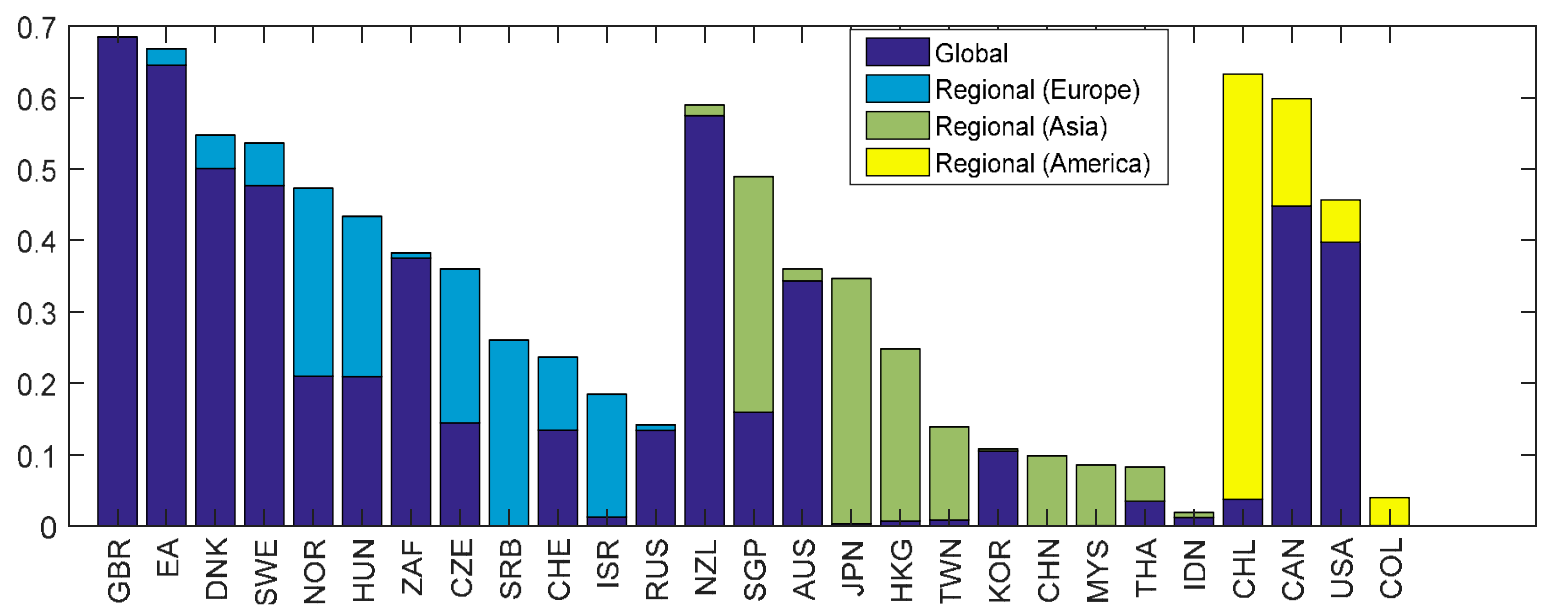

Source: See Appendix

Note: The figure illustrates the $s y n c h_{i}$ defined in the equation (3) for each country by region. In the figure, the contribution of the global factor is shown as the dark blue bar while the contribution of the regional factor is shown as the light blue bar (Europe), the green bar (Asia), and the yellow bar (North and South America).

Figure 6. Contribution of Global and Regional Factors in Asian House Price Growth
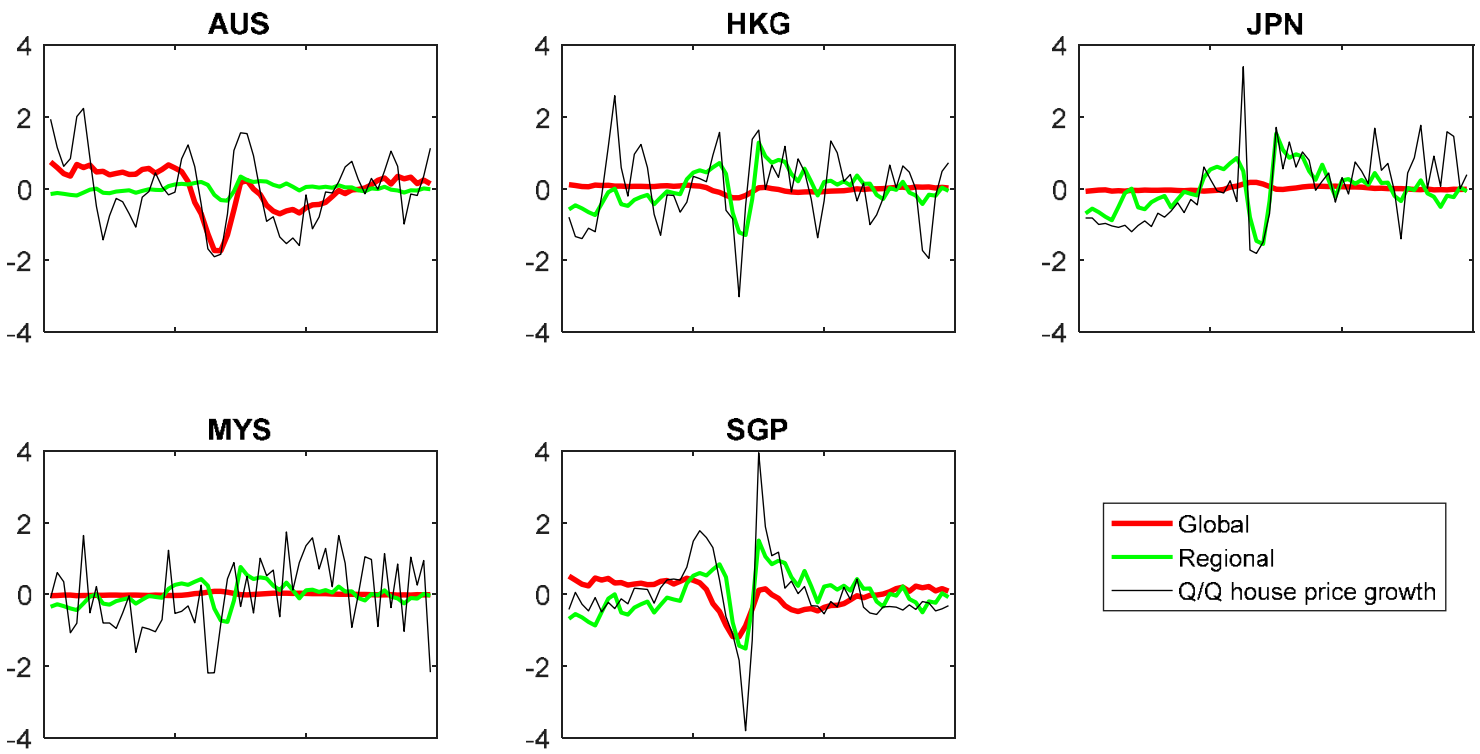

Source: See Appendix

Note: The figure shows the developments in house prices for selected Asian countries along with the global and regional factor multiplied by the factor loading (i.e., $\lambda_{g, i, t} g_{t}$ and $\lambda_{k, i, t} r_{k, t}$; the red and green lines in the figure). 
Figure 7. Global Factor for the City-Level Data and the Country-Level Data

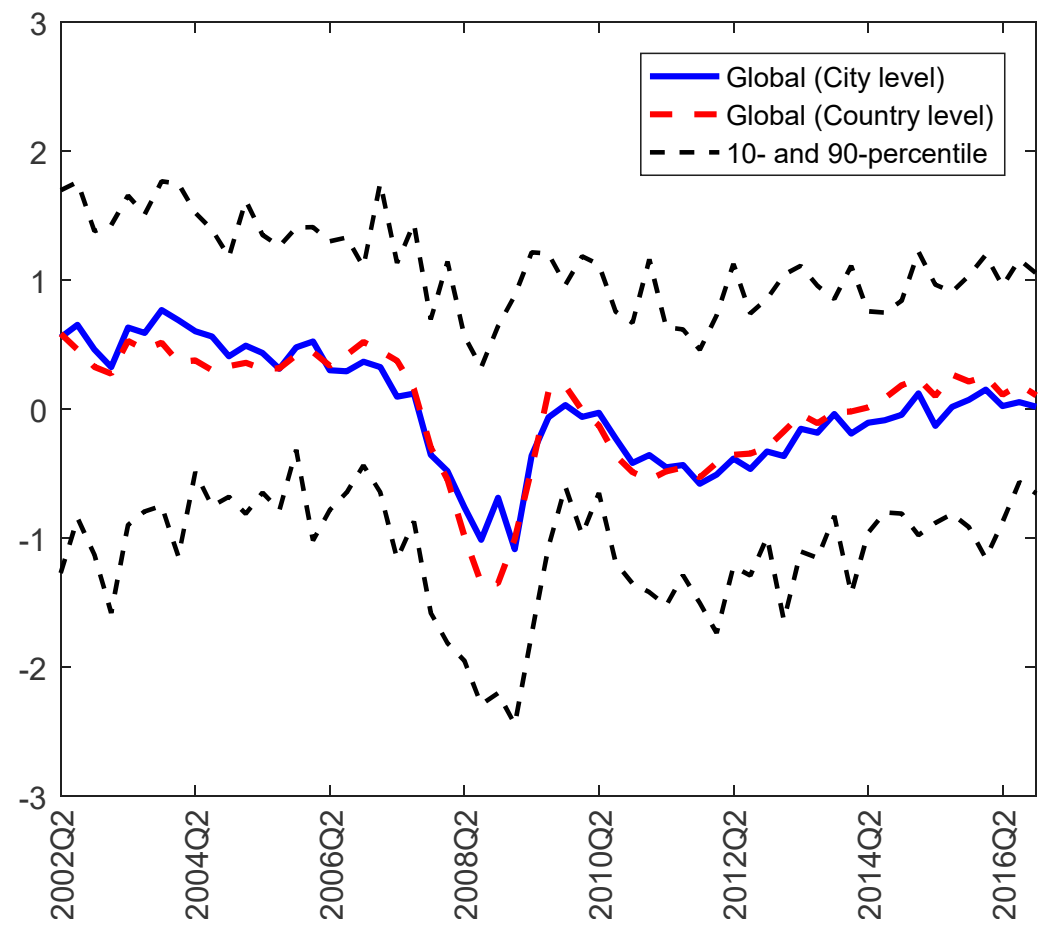

Source: See Appendix

Note: The figure shows the developments in the global factor extracted from the city-level data (the blue solid line) along with the global factor extracted by the country-level data (the red dashed line). 
Figure 8. Contribution of Global and Regional Factors in Selected Cities
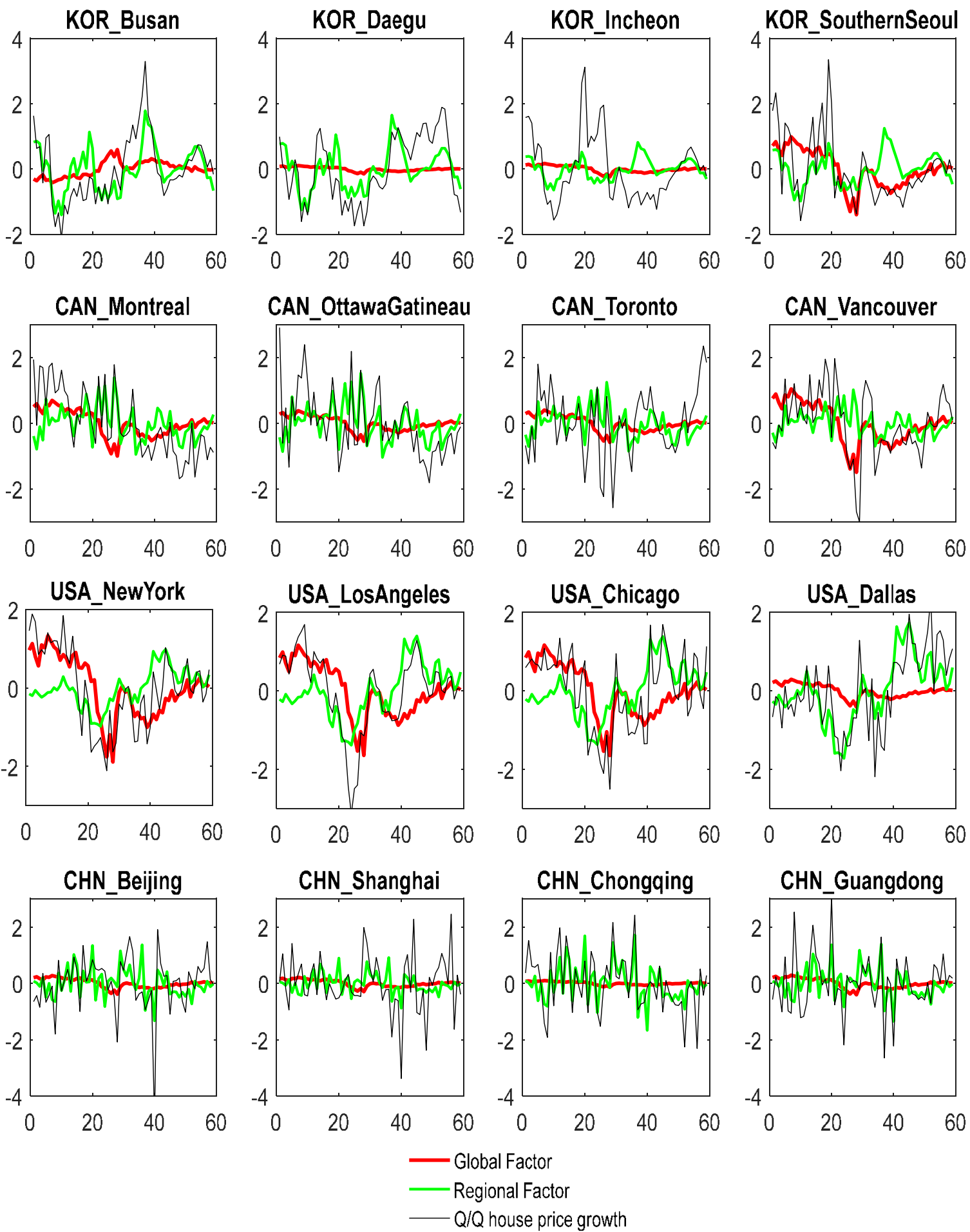

Source: See Appendix

Note: The figure shows the developments in house prices for a few large cities in KOR, CAN, USA, and CHN, along with the global and country factor multiplied by the factor loadings (i.e., $\lambda_{g, i, t} g_{t}$ and $\lambda_{k, i, t} r_{k, t}$; the red and green solid lines in the figure). 
Figure 9. House Price Synchronization and Financial Openness
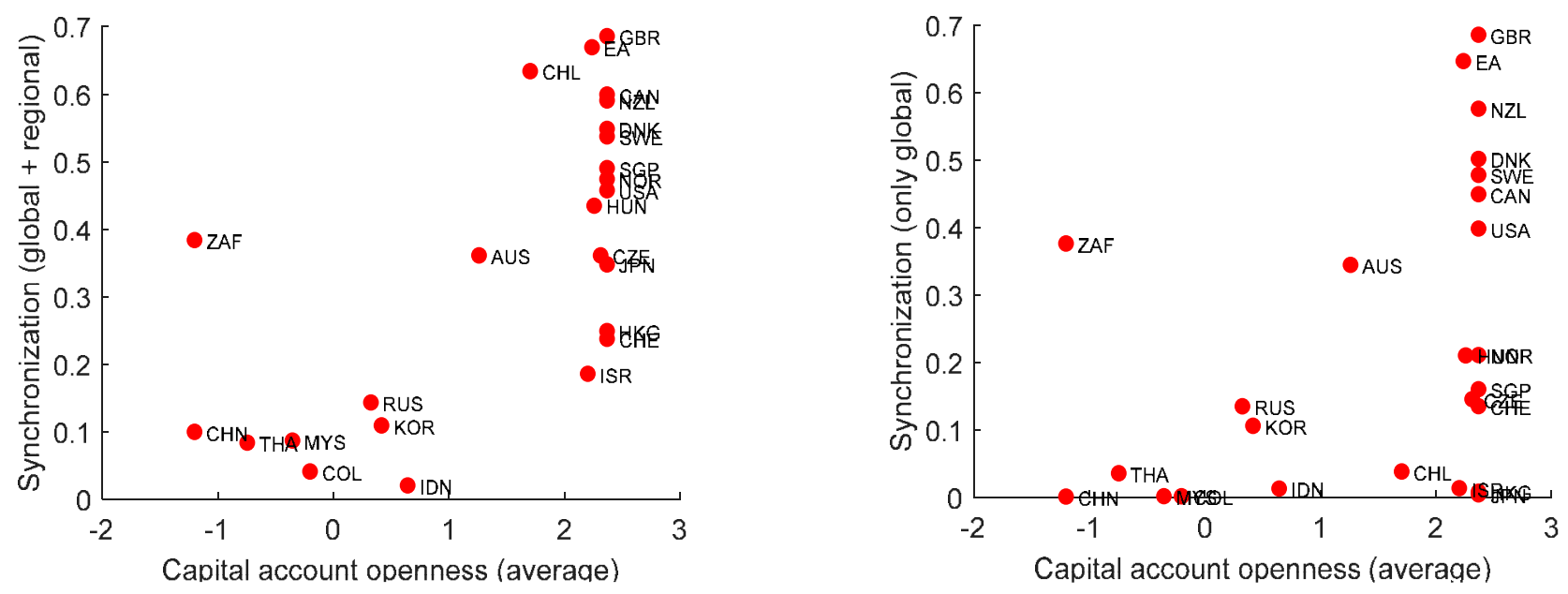

Source: See Appendix

Note: The figure illustrates the scatter plots of $\operatorname{synch}_{i}$ against financial openness. The left chart uses only the global factor for computing $s_{y n c h}$ while the right chart uses both the global and regional factor for computing synch $_{i}$. 
Table 1: Estimation Result for the Panel Regression

\begin{tabular}{|c|c|c|c|c|c|c|}
\hline \multirow{2}{*}{$\begin{array}{l}\text { Dependent Variable: House Price } \\
\text { Synchronization }\end{array}$} & \multicolumn{2}{|c|}{15 years } & \multicolumn{2}{|c|}{20 years } & \multicolumn{2}{|c|}{25 years } \\
\hline & $(1)$ & $(2)$ & (3) & (4) & (5) & (6) \\
\hline \multirow[t]{2}{*}{ Financial Openness } & $0.06691 * *$ & 0.02904 & $0.06220 * * *$ & $0.04354 * * *$ & $0.07481^{* * *}$ & $0.06670 * * *$ \\
\hline & $(0.02387)$ & $(0.02321)$ & (0.01585) & $(0.01477)$ & $(0.01578)$ & (0.01289) \\
\hline \multirow[t]{2}{*}{ Trade Openness } & $0.00911 * *$ & $0.00658 * *$ & $0.01096 * * *$ & $0.00891^{* *}$ & $0.00779 * * *$ & $0.00699 * * *$ \\
\hline & $(0.00394)$ & $(0.00312)$ & $(0.00351)$ & $(0.00334)$ & $(0.00141)$ & $(0.00184)$ \\
\hline \multirow[t]{2}{*}{ Log(Output) } & 0.22121 & $0.39513 * *$ & $0.27416^{* *}$ & $0.40820 * * *$ & $0.23717^{*}$ & $0.32661 * * *$ \\
\hline & $(0.13475)$ & $(0.15312)$ & (0.11590) & $(0.14007)$ & (0.11904) & (0.09859) \\
\hline \multirow[t]{2}{*}{ Inflation } & 0.02439 & 0.02159 & 0.00052 & 0.00253 & -0.00340 & -0.00260 \\
\hline & (0.02069) & $(0.02898)$ & $(0.00643)$ & $(0.00962)$ & $(0.00324)$ & $(0.00393)$ \\
\hline \multirow[t]{2}{*}{ Variance of idiosyncratic factor } & & $-0.16292 *$ & & -0.11162 & & -0.05319 \\
\hline & & $(0.08650)$ & & $(0.08338)$ & & $(0.06079)$ \\
\hline \multirow[t]{2}{*}{ Constant } & $-1.31628^{* *}$ & $-1.68169 * * *$ & $-1.53109 * * *$ & $-1.84651 * * *$ & $-1.23922 * *$ & $-1.51223^{* * *}$ \\
\hline & $(0.51871)$ & $(0.54940)$ & $(0.43175)$ & $(0.52551)$ & $(0.48204)$ & $(0.37440)$ \\
\hline Observations & 1,861 & 1,861 & 1,645 & 1,645 & 1,357 & 1,357 \\
\hline R-squared & 0.38823 & 0.46960 & 0.47414 & 0.51310 & 0.59165 & 0.60401 \\
\hline Number of country & 19 & 19 & 19 & 19 & 19 & 19 \\
\hline
\end{tabular}

Robust standard errors in parentheses

*** $p<0.01, * * p<0.05, * p<0.1$

Note: The table shows the estimation results for the panel regression for 19 countries from 1971:Q1 to 2016:Q4. The dependent variable is the synchronization measure defined in the equation (3) computed by the rolling window of 15 years, 20 years, and 25 years. The financial openness and the trade openness are proxied by the weighted average of the Chinn-Ito index and the ratio of trade volume to GDP, repectively. The variance of idiosyncratic factor is the realized volatility of the counry specific factor for the corresponding window. The explanatory variables include the country fixed effect and year dummies. The standard errors in parentheses are those which account for clustering of countries. 
Table 2: Estimation Results for the Cross Sectional Regression

\begin{tabular}{|c|c|c|c|c|c|c|}
\hline \multirow{2}{*}{$\begin{array}{l}\text { Dependent Variable: House Price } \\
\text { Synchronization }\end{array}$} & \multicolumn{3}{|c|}{ Only global factor } & \multicolumn{3}{|c|}{ Global and regional factor } \\
\hline & (1) & $(2)$ & (3) & (4) & (5) & (6) \\
\hline \multirow[t]{2}{*}{ Financial Openness } & $0.0803^{* *}$ & 0.0077 & -0.0190 & $0.1153^{* * *}$ & $0.0786 * *$ & 0.0611 \\
\hline & (0.0319) & $(0.0393)$ & $(0.0458)$ & $(0.0261)$ & $(0.0353)$ & $(0.0431)$ \\
\hline \multirow[t]{2}{*}{ Trade Openness } & -0.0010 & -0.0010 & -0.0006 & -0.0005 & -0.0004 & -0.0002 \\
\hline & $(0.0005)$ & $(0.0005)$ & $(0.0005)$ & $(0.0004)$ & $(0.0004)$ & $(0.0005)$ \\
\hline \multirow[t]{2}{*}{ Dummy for $A E$} & & $0.2614 * *$ & $0.2662 * *$ & & 0.1321 & 0.1224 \\
\hline & & $(0.0985)$ & $(0.1045)$ & & $(0.0883)$ & $(0.0985)$ \\
\hline \multirow[t]{2}{*}{ dLog(Output) } & & & -0.1578 & & & -0.0881 \\
\hline & & & (0.1119) & & & $(0.1054)$ \\
\hline \multirow[t]{2}{*}{ Inflation } & & & 0.0685 & & & 0.0071 \\
\hline & & & $(0.0880)$ & & & $(0.0829)$ \\
\hline \multirow[t]{2}{*}{ Constant } & $0.1945 * *$ & $0.1589 * *$ & 0.2419 & $0.2247^{* * *}$ & $0.2067^{* * *}$ & 0.2857 \\
\hline & $(0.0710)$ & $(0.0643)$ & $(0.1621)$ & $(0.0579)$ & $(0.0576)$ & $(0.1527)$ \\
\hline R-squared & 0.2178 & 0.3862 & 0.4083 & 0.4249 & 0.4555 & 0.4202 \\
\hline Number of country & 25 & 25 & 25 & 25 & 25 & 25 \\
\hline
\end{tabular}

$* * * p<0.01, * * p<0.05$

Note: The table shows the estimation results for the cross-sectional regression for 25 countries from 2002: Q1 to 2016: Q4. The dependent variable is the two types of synchronization measure defined in the equation (3) computed by the whole sample, the one is based only on the global factor and the other is based on both the global and regional factor. The financial openness and the trade openness are proxied by the average of the Chinn-Ito index and the ratio of trade volume to GDP, repectively. The standard errors are provided in parentheses. 